\title{
Emergency architecture. Modular construction of healthcare facilities as a response to pandemic outbreak
}

\author{
Marina Smolova*1, and Daria Smolova ${ }^{2[0000-0002-2297-0505]}$ \\ ${ }^{1}$ Kazan State University of Architecture and Engineering, 420043 Kazan, Russia \\ ${ }^{2}$ NFOE Inc., QC H2Y 2W7 Montreal, Canada
}

\begin{abstract}
Emerging infectious diseases originating from wildlife species continue to demolish humankind leaving an imprint on human history. December 2019 has marked the emergence of a novel coronavirus named SARS-CoV-2 (Covid-2019) originated in China in the city of Wuhan. Drastic emergence and spread of infectious disease have shown to appear in highly densified areas causing rapid spread of epidemic through population movement, transmission routes, major activity nodes, proximity, and connectivity of urban spaces. An extreme number of cases rising throughout the world caused space unavailability in healthcare facilities to serve patients infected with Covid-2019, therefore urging for innovative emergency management response from construction and architecture industry. Prefabricated modular construction has been widely utilized around the globe assembling rapid response facilities after catastrophic events such as tornadoes, hurricanes, and forest fires. An increasing number of Covid-2019 cases demanded effective and compressed implementation of medical centres to provide expeditious and secure healthcare. The paper examines the potential of standardization of modular construction of hospitals as a response to current and potential pandemic outbreaks. The research provides fundamental planning requirements of isolation units and their design flexibility as a key to rapid emergency solution.
\end{abstract}

Keywords. Modular construction, prefabrication, prefabricated construction, emergency architecture, healthcare facilities, hospitals, prefabricated architecture, Covid-2019.

\section{Introduction}

Wuhan - the centre of Covid-2019 origination, considered to be the largest city in Central China and the central core for commerce and industry with high connectivity to international airports and proximity of people in living environments that amplified disease capacity [1]. The outbreak of Covid-2019 began during the Chinese Spring Festival, which caused an enormous acceleration of population movement resulting in the burst of infected people. January $21^{\text {st }}$ has shown 215 cases confirmed in China, including 198 cases in Wuhan region and 17 cases that spread to other cities such as Shenzhen as the first reported case outside of

${ }^{*}$ Corresponding author: smolova5@mail.ru 
Wuhan, Beijing, and Shanghai [2]. Dense urban areas, mass gatherings, and domestic transportations were former factors that influenced the speed, capacity, and transmission of the virus to other regions and countries.

A high number of cases caused by great population and lack of available spaces in hospitals required urgent response from authorities. Despite the similarity of Covid-2019 spread patterns around the world, cities responded differently thus resulting in distinct and innovative design solutions for healthcare systems. In order to provide health services, China has transformed conference centres and stadiums into shelters for medical care [3]. To host huge numbers of people Huoshenshan and Leishenshan hospitals were constructed using prefabricated modular units within few days after Wuhan outbreak began [4].

Modular construction method indeed differs from the conventional construction process. Modules are built and prefabricated off-site and then transferred and assembled into a structure at their final destination [5]. Modular units can be assembled as a set of volumetric elements including walls, ceilings, and floors on-site, or can be delivered fully completed for rapid construction.

Modular prefabricated construction has been widely used to save lives influenced by global warming calamities serving the urgent and temporary shelters. Nowadays, living in an unpredictable world, modular architecture allows prompt and efficient response permitting to save greater number of lives. In comparison to conventional construction process, utilization of prefabricated units is more efficient when rapid construction is necessary, which allows to cover big areas and provide medical care to people in need.

Authors believe that modular construction serves a great potential in providing emergency response in a new pandemic era. The model of the Leishenshan construction process has accelerated and promoted the integration of modular units into emergency construction worldwide, therefore developing an innovative design approach in combatting Covid-2019 virus. Preliminary research has shown the lack of supportive materials of modular hospital design, which highlights the importance of further research.

The paper focuses on the application of modular design of Leishenshan hospital, which has accelerated the new development of modular unit systems. The paper is based on innovative design technologies and their reflection on the efficiency and utilization of hospitals during Covid-2019 pandemic. Following that, the research highlights the essential information about the design standards and specifications required in the design of modular systems. Additionally, it indicates important sanitary requirements specific to the construction of virus-related hospitals.

The paper aims to indicate the potential of modular construction of temporary hospitals, therefore creating innovative preparation measures. Authors believe that modular construction of hospitals will allow not only a better preparedness for future viruses but provide more flexibility of design serving the potential for hospital expansion and rapid delivery of separate modular healthcare facilities.

\section{Materials and methods}

To understand the specificity of prefabricated hospital design, the paper provides in-detail constriction and design process of Leishenshan hospital. It highlights essential data covering the beginning of the construction process, implementation, and its lifetime utilization. Following analysis includes plans and schemes, which highlight necessary design standards of modular unit hospital construction, consequently identifying fundamental requirements of design.

\subsection{Construction of Leishenshan hospital}

Leishenshan hospital was built as an emergency response to provide healthcare to patients infected with the novel Covid-2019 virus. The hospital was designed by Zhongnan 
Architectural Design Institute and later constructed by China Construction Third Engineering Bureau [6]. The hospital included isolating units' of 1600 beds located on a $79900 \mathrm{~m}^{2}$ covering the area of 21.97 ha [6]. To reduce the workload and accelerate the project, engineers and architects have used modular prefabricated systems. A steel structure was utilized as a primary modular assembly delivering various functions adopted to host operations in full isolation [6].

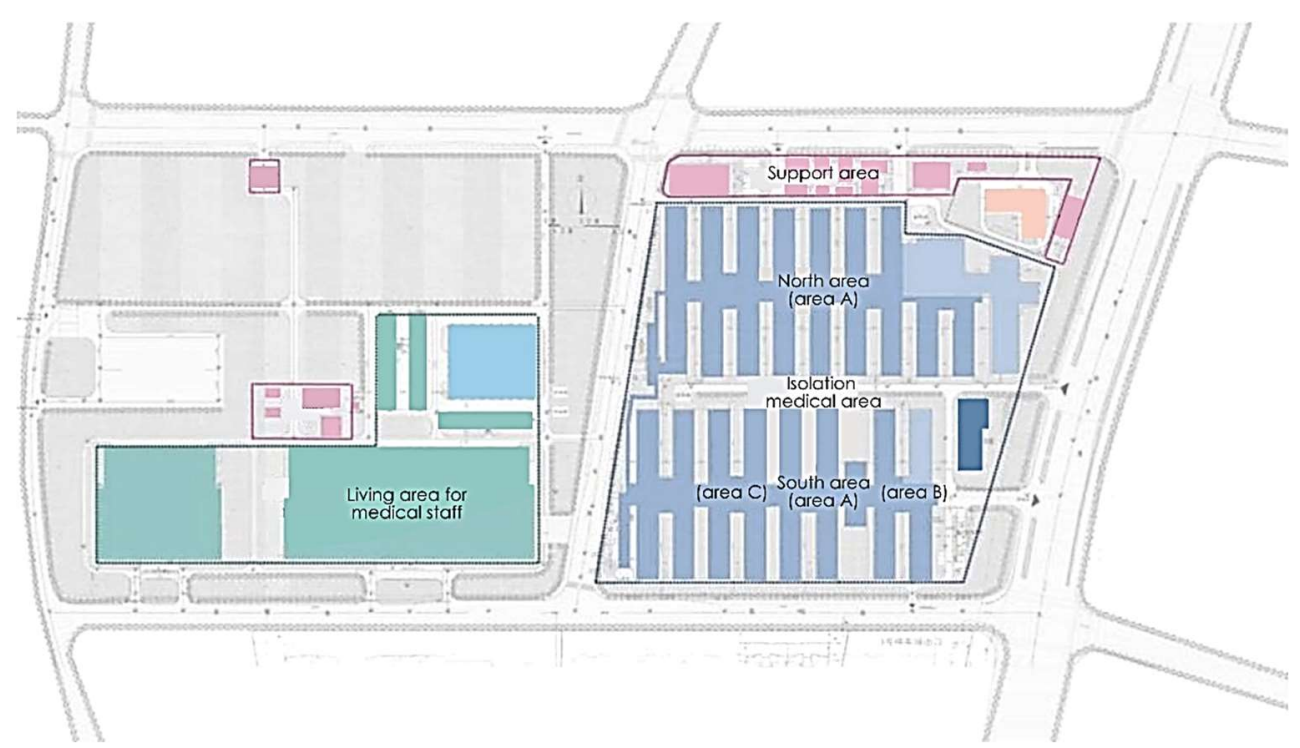

Fig. 1. Functional zoning of Leishenshan hospital [7].

The construction process combined the assembly of modules on-site fitting into the structure where innovative BIM technologies assisted in planning and precise hospital formation. Despite the overall complexity of the task and compressed delivery time, the construction of healthcare facilities for the treatment of infectious diseases is complex and requires not only prefabrication units but the use of modern BIM technologies and cooperation off and on-site.

During the design stage architects and engineers integrated two types of modules with dimensions of $3 \times 6 \times 2.9 \mathrm{~m}$ and $2 \times 6 \times 2,9 \mathrm{~m}$ [6]. Modular units adopted a skeleton system composed of composite board walls as main elements [6]. The utilization of a composite system allows rigidity, safety, stability, and durability of the entire structure. To form the module, walls, ceilings, and floors panels included glass fiber insulation and steel plate finishes [6]. Each modular unit is well insulated and equipped with a drainage system placed in corners.

The construction process of Leishenshan hospital took ten days and was subdivided into several stages. As shown on fig. 2, implementation process consists of several stages. Initial preparation includes work of excavators and bulldozers for levelling the ground. When the ground is flat, sand is being distributed on the ground into layers combining geotextile fabric and waterproofing materials in between to form the basis for foundation. Following that, concrete foundation is poured into the framed area with pillars for further waste drainage system. When the foundation is set, a skeleton of the units is placed accordingly to the plan. Consequently, skeleton modules being completed with prefabricated panels and essential electrical, medical, and ventilation systems, after which beds and other equipment can be placed. 


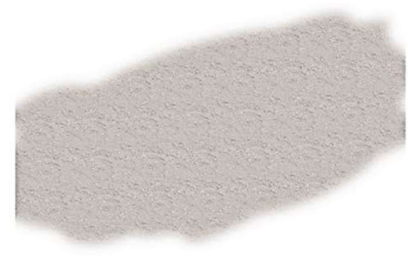

1. Ground levelling

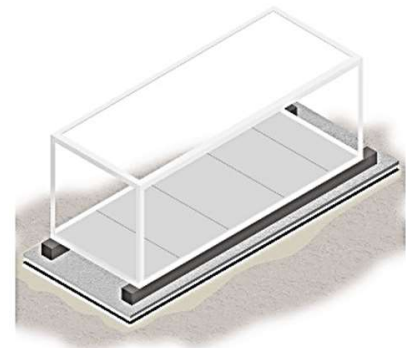

4. Skeleton frames

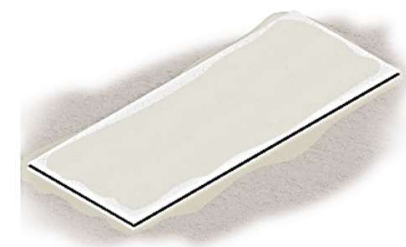

2. Sand, geotextile layers, waterproofing

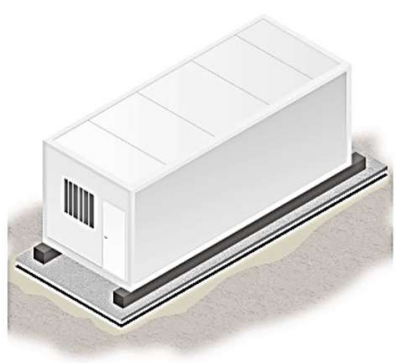

5. Prefabricated panels

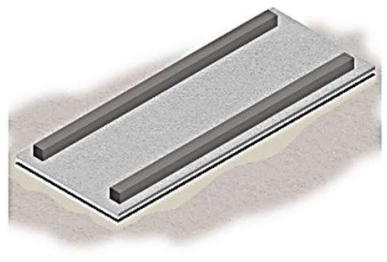

3. Concrete foundation, pillars

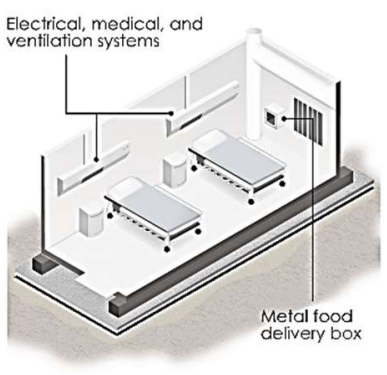

6. Equipment, electrical, medical, and ventilation systems

Fig. 2. Hospital implementation process [8].

\subsection{Typology and requirements}

In practice, modular units can be subdivided (fig. 3) into load-bearing wall modules and corner post-supported modules [9-11]. Load-bearing modules allow load distribution to foundation through walls, while corner post modules transfer load through corner post [11]. Corner post modules allow construction of bigger open spaces therefore modules can be placed on top of each other for necessary ceiling height [10].

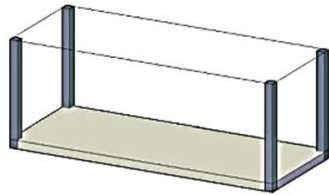

1. Corner supported modules

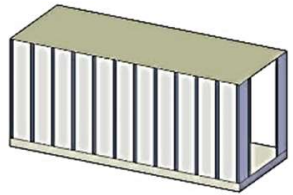

2. Wall supported modules

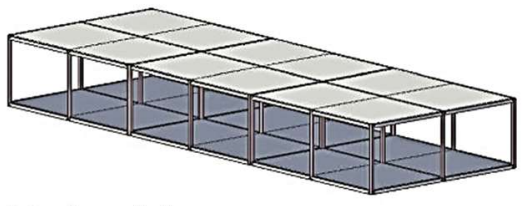

3. Implementation

Fig. 3. Types of load distribution in modular units [5].

The construction of healthcare facilities with full isolation is specific and, therefore demands a functional zoning subdivision (fig. 4). These healthcare facilities include controlled access, management of contaminated waste, and enclosing in-unit conditions including ventilation, humidity, and temperature levels [12]. Additionally, healthcare facilities require an integration of buffer areas between the isolation wards, and spaces for acute healthcare equipped with oxygen, negative pressure, and suction systems [12].

According to standards of healthcare facilities working in full isolation, Leishenshan hospital is subdivided into clean, semi-contaminated, and contaminated areas. Movement channels adopt the subdivision of patient and medical staff zones [6]. Movement pattern is separated between the clear, non-contaminated zones, and infected zones to exclude potential contamination throughout the channels. Additionally, layout should include the subdivision of medical staff movement, delivery, and patient channel [13, 14]. Studies show that to prevent environment from greater risk exposure, number of edges and corners should be minimized, the equipment should be made of easily cleanable surfaces and materials [15]. 


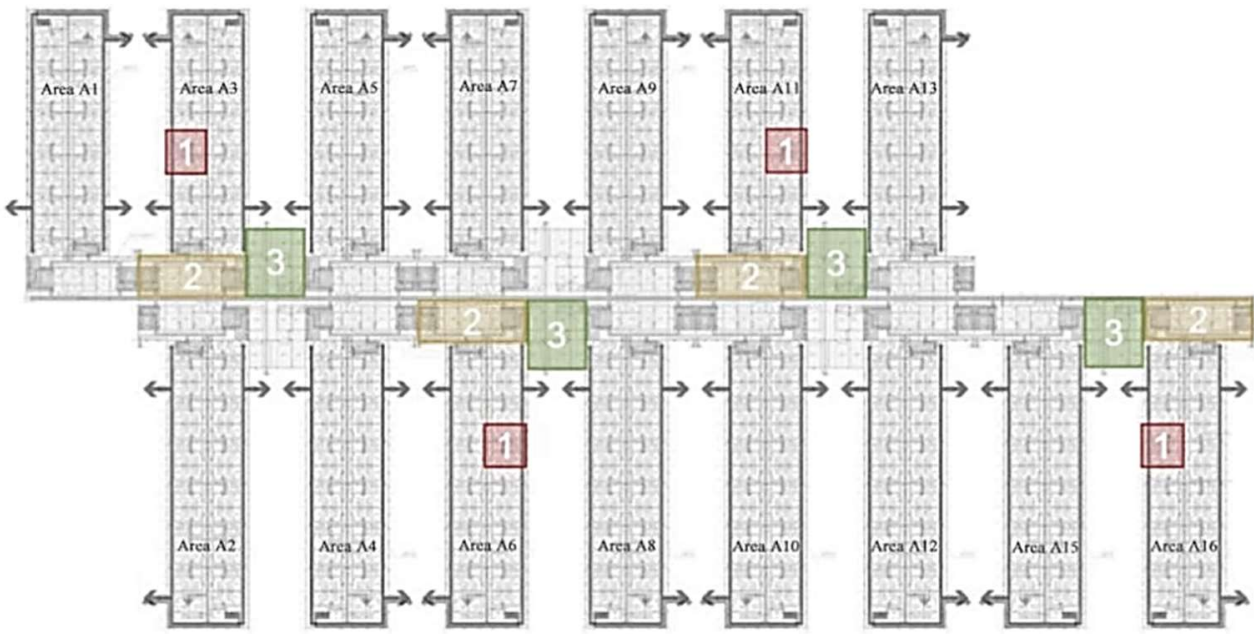

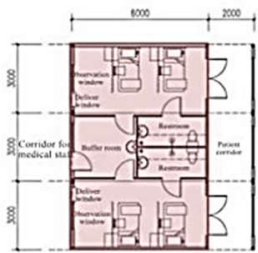

Module № 1

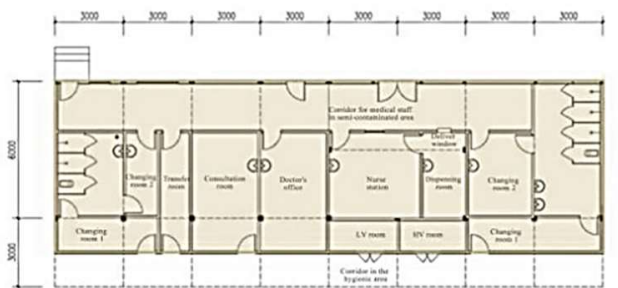

Module № 2

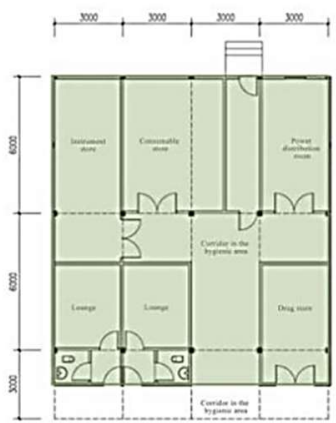

Module № 3

Fig. 4. Functional subdivision of modules [7].

In the construction of healthcare facilities for respiratory viruses, ventilation requires extra attention. Generally, three types of ventilation can be integrated into hospital construction: natural ventilation, mechanical ventilation and mixed ventilation systems. Uniform ventilation connected through modules can cause potential contamination. Based on that, it is recommended to utilize ventilation, which is designed individually for each unit excluding the possibility of further contamination. Studies suggest that to minimize exposure of contamination, high air change rate and low placement of openings should be considered [16-18].

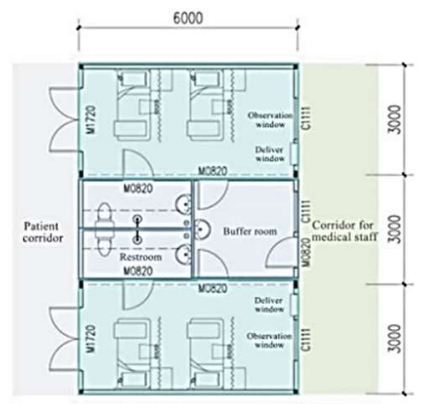

1. Basic Ward Module

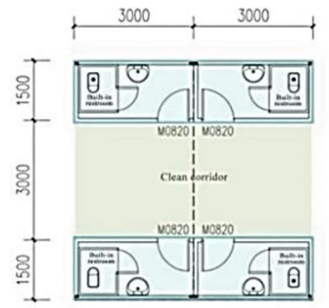

2. Distribution Room 2. Distribution Room
Small Restroom for Medical Staff

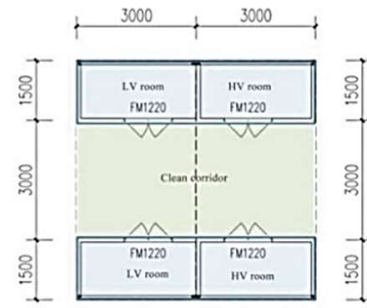

3. Distribution Room

Fig. 5. Models of hospital modules [5]. 
Functional zoning of temporary hospitals depends on the arrangement and spatial layout. Spatial zoning is primarily based on the organization of isolation wards and can take four forms (fig. 7). As can be seen on fig. 7 modules allow flexibility of zoning layout providing less potential of contamination between contaminated and non-contaminated passages. Crossing type is considered to be the most common type, which allows short traffic flow and less concentration of contamination. Alternating type provides better lighting and connection of isolation units with outdoor spaces serving potential for design of exterior gardens [19]. Dogleg is an $L$-shaped modular system, with relatively poor efficiency of space and disorganized movement throughout the building, which can cause greater exposure to virus. Diagonal type provides clear traffic movement, however, requires more time to move between the zones $[19,20]$.

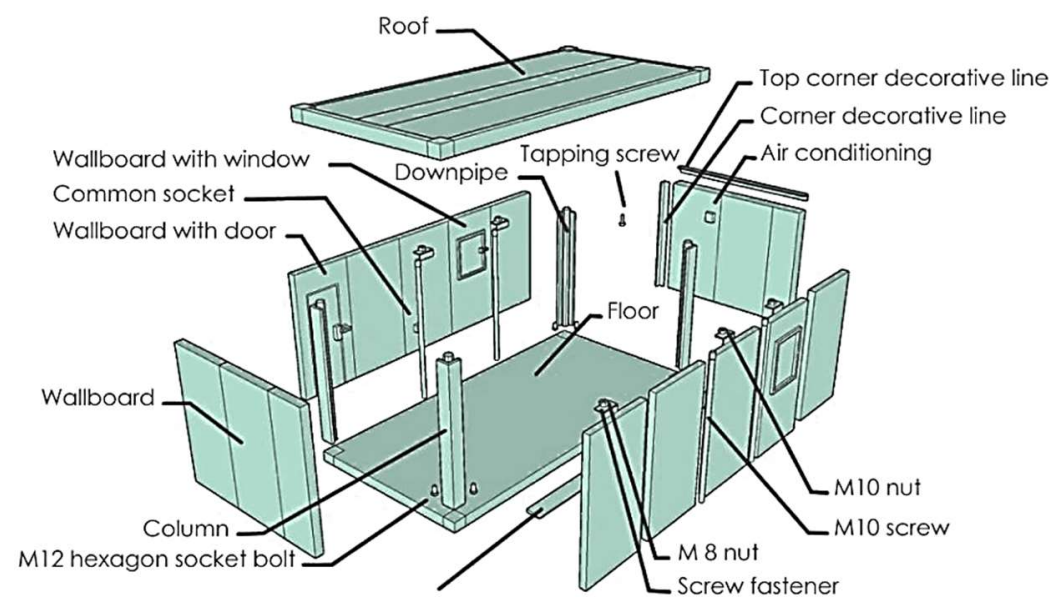

Fig. 6. Components of modular unit [6].

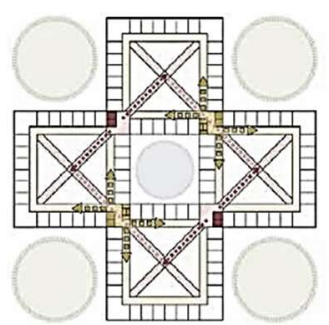

1. Crossing

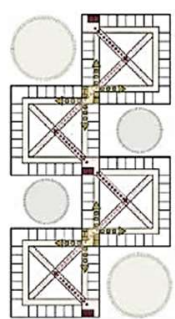

2. Alternating

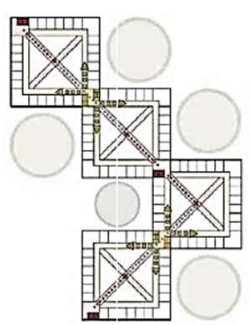

3. Dogleg

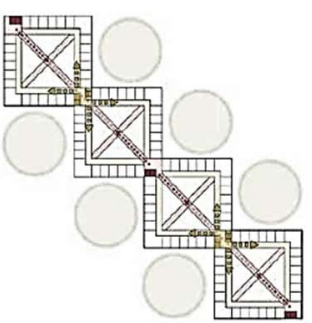

4. Diagonal

Fig. 7. Planning arrangement of modules [19].

\section{Results}

Undertaken analysis of modular construction of Leishenshan hospital helped to identify specific fundamental design requirements for providing medical care to people infected with respiratory virus. Despite that fact that modular construction allows great flexibility of design, functional zoning of hospitals will depend on the type of the virus, which will then be reflected in the plan of units and subdivision of areas. As a result, the research helped identify necessary subdivision of temporary hospitals into three main movement passages: contaminated, semi-contaminated and clear zones. Based on that, the contact between medical staff and patients is greatly minimized. On top of that, the study of Leishenshan hospital helped to indicate important stages of implementation, beginning from initial ground 
and foundation preparation, and proceeding to unit assembly. The paper examined four most common types of modular composition including crossing, alternating, dogleg and diagonal systems. In result, it provided an overview of potential design adaptability of units into existing settings. Presented materials in the paper helped to identify necessary dimensions of units and equipment, as well as the components of modular units. Subsequently, conducted materials combine necessary information, which can be used in further research and application of prefabricated units as a response to future possible pandemic outbreaks.

\section{Discussion}

Urban planners and architects were determined to find a solution for countries that lack availability in hospitals. Despite two constructed hospitals in China and various transformations of hotels and public spaces into medical stations, architects have proposed concepts of prefabricated efficient, and fast implementing structures that could potentially host infected people [21, 22].

The development of modular prefabricated systems plays a vital role in global preparedness to catastrophic events and occurrence of novel diseases where emergency response is needed, and therefore reflects on a number of lives that can be saved [23, 24].

The integration of modular systems allows shortening of construction time and amount of labour on the site compared to conventional construction process. Estimate delivery time of building, which consists of modular systems is based on the preparedness of modules ofsite, and therefore could be potentially prepared in advance in case of the emergency for a prompt response. On the other hand, buildings built following conventional construction process is organized layer by layer and require time to proceed to the next stage. Additionally, implementation of healthcare facilities with a conventional method depends on weather conditions, which can disrupt construction work during the process [19, 25].

The use of modular construction as a response to emergency situation allows flexibility of design and required materials [26, 27]. Despite the fact that modules can be composed of concrete, steel, and composite materials, creative ideas can be extracted and obtained from more affordable and accessible sources. Following the construction principle of Leishenshan hospital in China, architects and engineers brought creative ideas combining design and innovation.

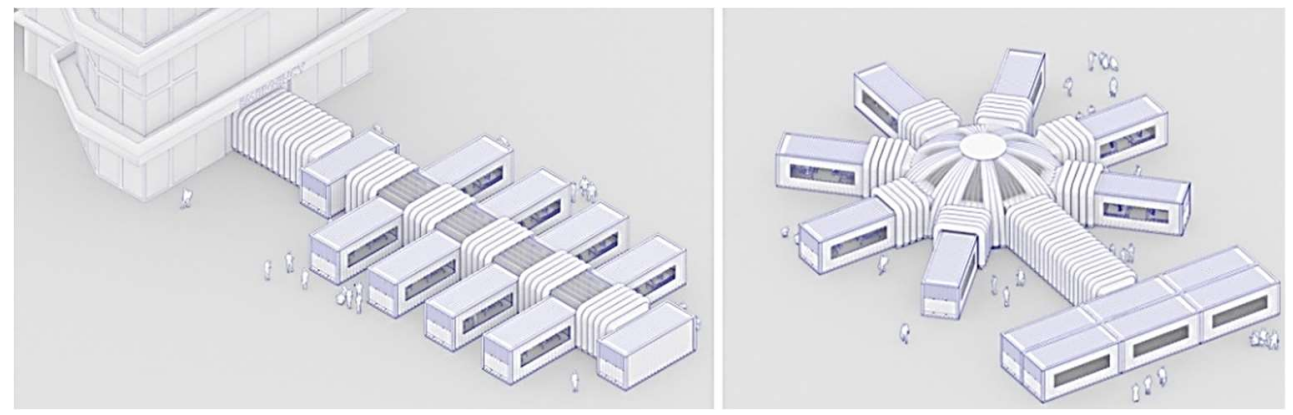

Fig. 8. Arrangement of CURA modules [28].

Italian architects Carlo Ratti and Italo Rota have used basic shipping containers as a main component that could be adapted and fixed to existing structures of hospitals or converted into «shipping communities» (fig. 8, 9) for medical treatments [28]. CURA Pods were designed and installed in hospital in Turin following modular principle. CURA modules can be placed as a separate self-standing system or as an expansion of existing hospital allowing continuation of ongoing medical treatments [29]. The connection between modules can be provided through inflatable tunnels, which can be potentially subdivided into regulating zones [30]. 

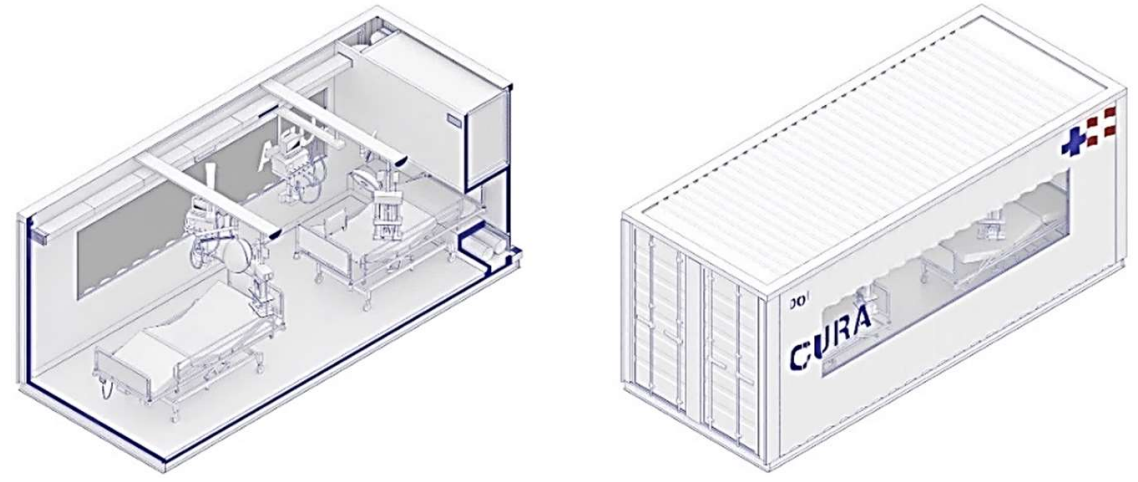

Fig. 9. CURA modules [28-30].

Another innovative modular approach was applied in the construction of Amsterdam Cancer Centre in Netherlands [19, 31]. The building consists of 256 modules (fig. 10) covering an area of $2000 \mathrm{~m}^{2}$. The hospital was designed as a free-standing modular building adjacent to existing cancer centre [19]. Containers as a main element of design were prepared and painted off-site and then consequently assembled together.
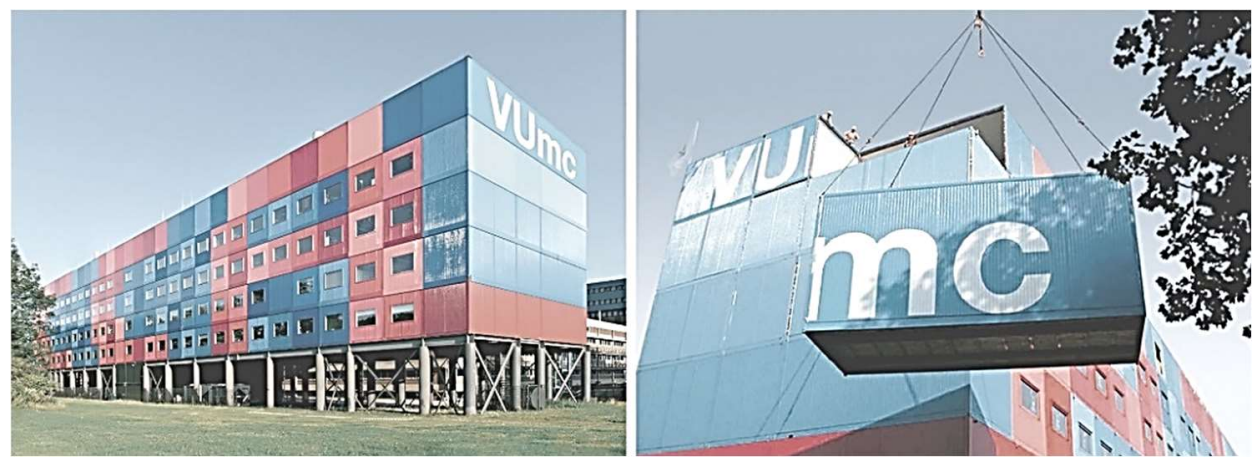

Fig. 10. Design and assembly of modular containers [19].

\section{Conclusion}

Living in a new era of pandemic, architects and engineers now take responsibility to provide rapid design solutions in emergency situations. It is now as never before important to develop a standardized design approach, which will allow quick response to pandemic outbreaks. The integration of modular construction into healthcare temporary facilities permits to provide dense urban areas with greater number of isolation units, thus minimizing space shortage in hospitals. Modular expansion of existing hospitals allows no disruption in ongoing functioning of healthcare facilities, which will greatly increase the efficiency of medical care response. Authors believe that prefabricated construction of healthcare units serves a great importance to the management of potential viruses in the future.

\section{References}

1. A. Wilder-Smith, C.J. Chiew, V.J. Lee. Can we contain the COVID-19 outbreak with the same measures as for SARS?, The lancet infectious diseases 20 (5), 102-107 (2020). DOI: 10.1016/S1473-3099(20)30129-8. 
2. S. Zhao, Z. Zhuang, J. Ran, J. Lin, G. Yang, L. Yang, D. He. The association between domestic train transportation and novel coronavirus (2019-nCoV) outbreak in China from 2019 to 2020: a data-driven correlational report, Travel medicine and infectious disease 33, 101568 (2020). DOI: 10.1016/j.tmaid.2020.101568.

3. S. Chen, J. Yang, W. Yang, C. Wang, T. Bärnighausen. COVID-19 control in China during mass population movements at New Year, The Lancet 395 (10226), 764-766 (2020). DOI: 10.1016/S0140-6736(20)30421-9.

4. W. Zhao, J. Zhang, M. Meadows, Y. Liu, T. Hua, B. Fu. A systematic approach is needed to contain COVID-19 globally, Science Bulletin, (2020). DOI: 10.1016/j.scib.2020.03.024.

5. P. Gatheeshgar, K. Poologanathan, S. Gunalan, I. Shyha, P. Sherlock, H. Rajanayagam, B. Nagaratnam. Development of affordable steel-framed modular buildings for emergency situations (Covid-19), Structures 31, 862-875 (2021). DOI: 10.1016/j.istruc.2021.02.004.

6. L.K. Chen, R.P. Yyan, X.J. Ji, X.Y. Lu, J. Xiao, J.B. Tao, L.Z. Jiang. Modular composite building in urgent emergency engineering projects: A case study of accelerated design and construction of Wuhan Thunder God Mountain. Leishenshan hospital to COVID-19 pandemic, Automation in Construction 124, 103555 (2021). DOI: 10.1016/j.autcon.2021.103555.

7. L. Wen-tao, Z. Song-min. Modularization, Standardization and Prefabrication, Rapid Construction of Leishenshan Hospital.

8. J. Wang, E. Zhu, T. Umlauf. How China built Two coronavirus hospitals in just over a week. Retrieved April 06, 2021, from https://www.wsj.com/articles/how-china-canbuild-a-coronavirus-hospital-in-10-days-11580397751. 2020

9. M.J. Hough, R.M. Lawson. Design and construction of high-rise modular buildings based on recent projects, Proceedings of the Institution of Civil Engineering 1726 , 37-44 (2019). DOI: 10.1680/jcien.18.00058.

10. R.M. Lawson, R.G. Ogden, R. Bergin. Application of modular construction in high-rise buildings, Journal of architectural engineering 18 (2), 148-154 (2012). DOI: 10.1061/(ASCE)AE.1943-5568.0000057.

11.J.Y.R. Liew, Y.S. Chua, Z. Dai. Steel concrete composite systems for modular construction of high-rise buildings, Structures 21, 135-149 (2019). DOI: 10.1016/j.istruc.2019.02.010.

12. Q. Gbadamosi, L. Oyedele, O. Olawale, S. Abioye. Offsite Construction for Emergencies: A focus on Isolation Space Creation (ISC) measures for the COVID-19 pandemic, Progress in Disaster Science 8, 100130 (2020). DOI: 10.1016/j.pdisas.2020.100130.

13. Q. Zhang, S. Cheng, Q. Cheng. Experience summary of a COVID-19 designated community hospital and its operation model, Panminerva medica (2020). DOI: 10.23736/S0031-0808.20.03908-7.

14. L. Aalto, P. Sirola, T. Kalliomäki-Levanto, M. Lahtinen, V. Ruohomäki, H. Salonen, K. Reijula. User-centric work environments in modular healthcare facilities, Engineering, Construction and Architectural Management (2019). DOI: 10.1108/ECAM-04-20180169.

15. M. Spagnolo, G. Ottria, D. Amicizia, F. Perdelli, M.L. Christina. Operating theatre quality and prevention of surgical site infections, Journal of preventive medicine and hygiene 54 (3), 131 (2013). DOI: 10.15167/2421-4248/jpmh2013.54.3.398

16. P.V. Nielsen, Y. Li, M. Buus, F.V. Winther. Risk of cross-infection in a hospital ward with downward ventilation, Building and Environment 45 (9), 2008-2014 (2010). DOI: 10.1016/j.buildenv.2010.02.017. 
17. Q. Bhatti, A. Wahab. Analysis and design of emergency field isolation hospital building using innovative rapidly construction prefabricated units to treat patients infected with COVID-19, Innovative Infrastructure Solutions 6 (2), 1-22 (2021). DOI: 10.1007/s41062020-00453-1.

18. U. Emmanuel, E.D. Osondu, K.C. Kalu. Architectural design strategies for infection prevention and control (IPC) in health-care facilities: towards curbing the spread of Covid-19, Journal of Environmental Health Science and Engineering, 1-9 (2020). DOI: 10.1007/s40201-020-00580-y.

19. Y. Li, X. Yang. Study on hospital design and its transition during pandemic situation, Politecnico di Torino (2021).

20. X. Li. Upgrade. Application of Roof and Wall Modules in Medical Construction Based on Prefabricated Interior Decoration Technology, Journal of Architectural Engineering 27 (2), 05021001 (2021). DOI: 10.1061/(ASCE)AE.1943-5568.0000455

21. A. Alraouf. The new normal or the forgotten normal: contesting COVID-19 impact on contemporary architecture and urbanism. Archnet-IJAR, International Journal of Architectural Research (2021). DOI: 10.1108/ARCH-10-2020-0249.

22. B. Maturana, A.M. Salama, A. McInneny. Architecture, urbanism and health in a postpandemic virtual world. Archnet-IJAR, International Journal of Architectural Research, (2021). DOI: 10.1108/ARCH-02-2021-0024

23. Y. Parsia, S. Sorooshian. A Decision-Making Algorithm for Rearchitecting of Healthcare Facilities to Minimize Nosocomial Infections Risks. International journal of environmental research and public health 17 (3), 855 (2020). DOI: 10.3390/ijerph17030855.

24. N.P. Pilosof. Building for change: Comparative case study of hospital architecture. HERD, Health Environments Research \& Design Journal, 1937586720927026 (2020). DOI: 10.1177/1937586720927026

25. M. Zhou, Y. Chen, X. Su, L. An. Rapid construction and advanced technology for a Covid-19 field hospital in Wuhan, China, Proceedings of the Institution of Civil Engineers 174 1, 29-34 (2020). DOI: 10.1680/jcien.20.00024.

26. C. Quintelli, M. Maretto, E. Prandi, C. Gandolfi, M. Zammerini, G. Gasco, R. Petrella. Coronavirus, city, architecture. Prospects of the architectural and urban design.

27. L. Wang. The new bud light steel system and the geometric shape evolution of light steel framework for COVID-19 patients appointed hospital (Huoshenshan hospital), Journal of Intelligent \& Fuzzy Systems (Preprint), 1-12. DOI: 10.3233/JIFS-189300.

28. Harrouk. Carlo Ratti CONVERTS shipping containers Into Intensive-Care pods for the Covid-19 pandemic. Retrieved April 06, 2021, from https://www.archdaily.com/936247/ carlo-ratti-converts-shipping-containers-into-intensive-care-pods-for-the-covid-19pandemic (2020).

29. T. Ravenscroft. Carlo Ratti Associati designs SHIPPING-CONTAINER intensive care units for coronavirus treatment. Retrieved April 06, 2021, from https://www.dezeen.com/ 2020/03/24/shipping-container-intensive-care-units-coronavirus-covid-19-carlo-ratti/ (2020).

30. N. Sönmez, B.T. Çavka. Transformation of Hospital Areas in the world after Covid-19 Pandemy. IDU SPAD'20 International Spatial Planning and Design Symposium, 273 (2020).

31. ArchiloversCom. (n.d.). Cancer centre amsterdam: Mvrdv. Retrieved April 06, 2021, from https://www.archilovers.com/projects/62389/cancer-centre-amsterdam.html. 